\title{
Organic Rankine cycle power generation technology development and Application
}

\author{
Hongyue Wang ${ }^{a}$, Zhiyuan Liu ${ }^{\text {b }}$ \\ School of Energy Power and Mechanical Engineering College, North China Electric Power \\ University, Hebei Baoding 071003, China \\ a1658263043@qq.com, b347435078@qq.com
}

Keywords: Organic Rankine cycle; waste heat recovery; the organic working fluids.

Abstract. Organic Rankine cycle is an important means of waste heat recovery technology, this paper is mainly review of organic Rankine cycle principle and system composition, and introduces some practical application of organic Rankine cycle.

\section{Introduction}

Low temperature waste heat temperature under 350 Celsius degrees is widespread in building material, metallurgy, power and other industrial processes. It is estimated that $1 \mathrm{KWH}$ of electricity can saved $4 \mathrm{~kg}$ water and $0.4 \mathrm{~kg}$ of standard coal using low temperature waste heat. For environmental reasons, the NDRC has stopped approving afterburning type of waste heat power generation project. Pure low temperature waste heat power generation technology become a trend in the future. The proposal made by National Energy Administration and the preferential policy established for the waste heat power station provide favorable condition for pure low temperature waste heat power generation technology. Organic Rankine cycle power generation technology (ORC) can be dated back to 1920s. With the problems of energy crisis becomes more serious, governments and researchers begin to pay attention on the problems. Compared with other pure low temperature waste heat power generation technology such as semiconductor thermoelectric power generation, thermal power generation and so on, ORC is less likely to be limited by the material and has high electrical efficiency. In this paper, the principle of ORC and circulating refrigerant selection is introduced. Moreover, the calculation and application of ORC are presented as well.

\section{The principle of ORC}

Since the circulating refrigerant is low boiling organic compounds, the ORC has many differences compared with the conventional steam Rankine cycle. Main equipment of conventional Rankine cycle includes steam boiler, steam turbine, condensers and pumps. Compared with conventional steam Rankine cycle system, ORC system does not need oxygen-extractor and other auxiliary equipment. It has small turbine size and eliminates overheating segment which simplify the structure of the boiler and save the investment cost.

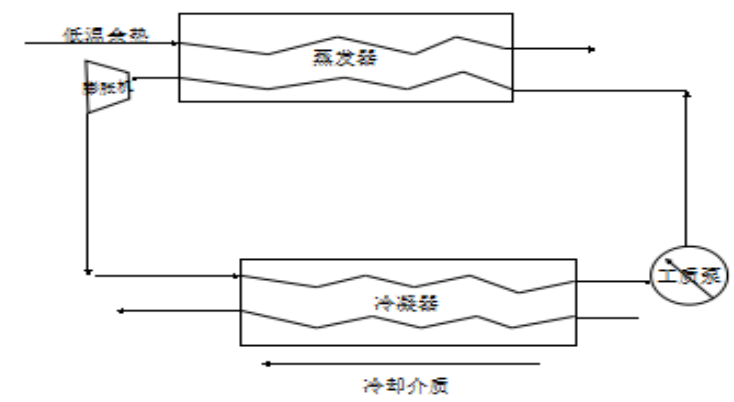

Figure 1 no heat ORC power system schematic diagram

According to Figure 1, the ORC expansion does not enter the wet area compared with the conventional steam Rankine cycle stage, so it doesn't need overheat the stage and other stages are 
similar to steam Rankine cycle.

ORC system performance is mainly related to refrigerants, heat exchanger performance and working condition. Optimization the circulatory system is the key to improve the ORC system performance. Currently, there is no national standards and norms for ORC system. Since 1970s, China has been developing the technology and device of ORC for years, however, there are no substantial improvements and institutions for ORC research. It still has a long way for China to make progress.

Recently, the evaluation methods for ORC system mainly use efficiency analysis, analysis of finite time thermodynamics and Exergy-economic analysis. These methods are the basis of ORC system optimization.

\section{Principle of circulating refrigerant selection}

Circulating refrigerant in the thermodynamic system has a great influence on system performance. Hence, the selection of circulating refrigerant and research on property are the foundation of ORC research. There is no standard for circulating refrigerant selection. However, the following statements need to be taken into consideration.

Environmental performance; in the early period, halogenated hydrocarbons is widely used in ORC and Refrigeration technology. But with the subsequent understanding of their role in destruction of the Ozone Layer, the world has stopped producing this kind of refrigerant

The reliability of refrigerant including toxic, inflammable, explosive, corrosive performance is need to consider.

Refrigerant critical temperature can't be too low or the condensing pressure will become very high.

The flow and heat transfer performances of circulating refrigerant are very important. Materials with good heat transfer and low viscosity are proposed.

The cost of circulating refrigerant should be as low as possible.

When the performance indicators and the heat source temperature is not the same, optimal refrigerants for ORC system is also different. Comparing different refrigerants refrigerant cycle performance is one of the most commonly used method. With the help of output power and system loss, Zhu et al. selected the refrigerant for geothermal ORC System. The results show that when geothermal temperature is at $60 \sim 80^{\circ} \mathrm{C}$, R601a has maximum net power; when the temperature is at $125 \sim 150^{\circ} \mathrm{C}$, R290 is the best refrigerant. Taken the volume flow rate, mass flow rate, toxicity, flammability, and environmental characteristics into consideration, 20 refrigerants are analyzed. The analysis shows that when the temperature is below $90^{\circ} \mathrm{C}, \mathrm{R} 134 \mathrm{a}$ is the best refrigerant.

\section{Tube heat exchange calculation}

In low temperature waste heat power generation system, heat exchanger takes the main part of the total investment costs. While designing for the heat exchanger, overall heat transfer coefficient is often calculated through convective heat transfer coefficient of heat exchange inside and outside. Calculation on outside heat exchange already has a mature correlation. The main problem lies in calculation on inside heat exchange

\subsection{Single - phase flow and heat transfer correlations}

Gnielinski correlation

$$
N u=\frac{(0.125 f)\left(\operatorname{Re}_{f}-1000\right) \operatorname{Pr}_{f}}{1+12.7 \sqrt{0.125 f}\left(\operatorname{Pr}_{f}{ }^{2 / 3}-1\right)}\left[1+\left(\frac{d_{i}}{l}\right)^{2 / 3}\right] c_{f}, f=\frac{1}{(1.82 \lg \operatorname{Re}-1.64)^{2}}
$$

The correlation is suitable for both laminar and turbulent flow

\subsection{The evaporator heat transfer correlation}

Varme Atlas correlation 


$$
\alpha=\alpha^{\prime}\left\{\left[(1-x)+1.2 x^{0.4}(1-x)\left(\frac{\rho^{\prime}}{\rho^{\prime \prime}}\right)^{0.37}\right]^{-2.2}+\left[\frac{\alpha^{\prime \prime}}{\alpha^{\prime}} r x^{0.01}\left(1+8(1-x)^{0.7}\right)\left(\frac{\rho}{\rho^{\prime \prime}}\right)^{0.67}\right]^{-2}\right\}^{-0.5}
$$

Where $\mathrm{x}$ is refrigerant dryness; $\mathrm{r}$ is the latent heat of refrigerant; Superscript symbol ' represents for saturated liquid phase and superscript symbol " represents for saturated gas phase.

\subsection{Heat transfer correlation in tube condenser stage}

As early as 1916, Nusselt has done some research on saturated gas heat transfer. Through modifying, horizontal tube condensation heat transfer calculation formula can be $N u=0.729\left[\frac{\lambda^{3} \rho_{1} g r}{\eta D_{o}\left(t_{s}-t_{w}\right)}\right]^{0.25}$.

Where $\lambda$ is the thermal conductivity coefficient of fluids; $\eta$ is the coefficient of dynamic viscosity.

\section{Application of ORC}

Besides low temperature waste heat in the industrial process, there is a large number of low temperature heat recovery can be used in ORC, such as LNG cold energy, geothermal energy, low temperature solar energy and ocean thermal energy.

\subsection{LNG Organic Rankine cycle power}

Figure 2 is the system architecture diagram of LNG ORC recovery utilization.

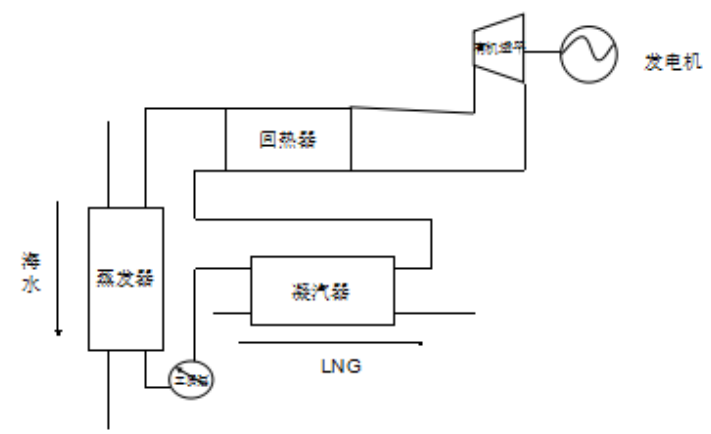

Figure 2 LNG cold energy ORC electricity principle diagram

ORC LNG cold exergy can be converted into electricity and warm up for the LNG making more rational use of energy.

\subsection{ORC biomass cogeneration}

Biomass energy is an international new energy research focus, and the biomass power generation ORC system is shown in Figure 3.

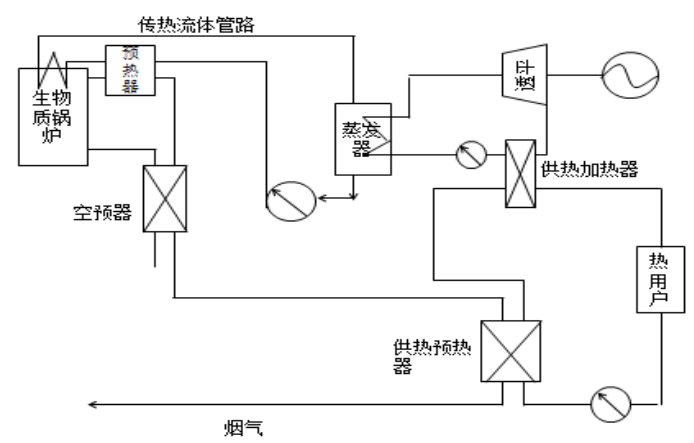

Figure 3 the biomass power generation ORC system

The system uses the energy step by step, therefore it has a strong advantage in energy saving, fuel reduction and the use of low-emissions technology. It can greatly reduce the pollutant emissions that about $40 \%$ emissions of pollutants can be reduced. 


\subsection{ORC in the low temperature solar energy technologies}

Solar energy conversion is regarded as the most ideal way for the future. Solar radiation can evaporate the refrigerant to gas which drives the turbine to work. The principle of ORC solar sower generation is shown in Figure 4.

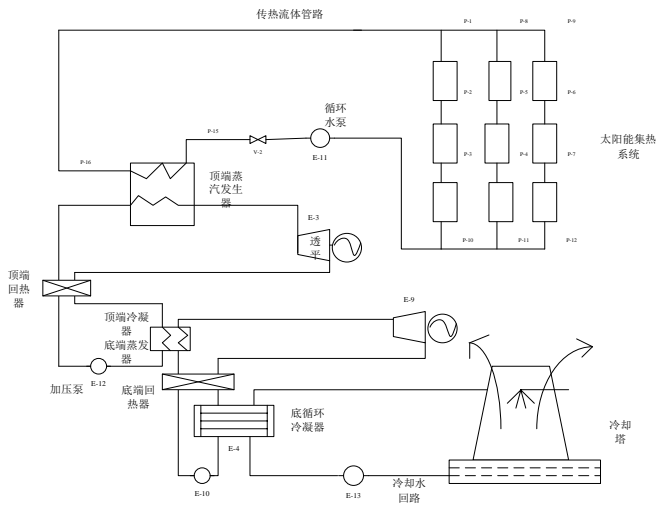

Figure 4 principle of ORC solar sower generation

Compared with the direct conversion of photoelectric, optical - thermal - electric systems can reduce system cost. The direct conversion of photoelectric is often limited by material. The current conversion efficiency is quite low. Conversely, the ORC solar power generation system does not have these kinds of problem. It is much easier to improve the efficiency of ORC than improve the photoelectric conversion rate.

\section{Summary}

Organic Rankine cycle technology for waste heat recovery is of great importance, but further research on ORC is still needed in order to bring its production on a large scale. Because of its advantages, in development of the next generation systems, it will play a significant role. Standardization for system design will be an urgent problem in the future.

\section{References}

[1] Wang Hua. Organic rankine cycle technology in low temperature waste heat power generation organic rankine cycle technology [M] Beijing: Science Press, 2010. 149-155

[2] ZHU JiangLU Yuan-weiMA Chong-fangWU Yu-ting, Working fluid selection for organic rankine cycle (ORC) in low temperature geothermal power generation system [J] Renewable Energy, 2009, 02: 76-79.

[3] Wang Zhiqi Experimental study and dynamic characteristic simulation for organic rankine cycle in low temperature waste heat power generation system and [D]. Central South University, 2012.

[4] Wang Zheng Cui Chao .Design and Analysis on Low-temperature Waste Heat Power Generation Using Organic Rankine Cycle[J] Power \& Energy, 2013,04: 321-324. 